\title{
Educational Difficulties Of Totally Visual Impaired Students At School Level Of The Jawahar Blind School, Chimakurthy Ongole Mandal, Prakasam District - A Case Study In Andhra Pradesh
}

\author{
Jalli. Pothuraju', B.Chaitanya Kiran Kumar², Kakumanu. Suneetha ${ }^{3}$, \\ Hemalatha.Anchipakula ${ }^{4}$ \\ ${ }^{I}$ Ph.D. Research Scholar, Dept of Education, Acharya Nagarjuna University, Nagarjuna Nagar, Guntur District \\ - 522510. Andhra Pradesh, INDIA. \\ ${ }^{2}$ Ph.D. Scholar, Dept of History and Archaeology, Acharya Nagarjuna University, Nagarjuna Nagar - 522510. \\ ${ }^{3}$ M.Ed Student, Dept of Education, Acharya Nagarjuna University, Nagarjuna Nagar - 522510. \\ ${ }^{4}$ Ph.D. Scholar, Dept of History and Archaeology, Acharya Nagarjuna University, Nagarjuna Nagar - 522510.
}

\begin{abstract}
Education is the development of the abilities of the mind. The term education is commonly used in various fields of knowledge. The meaning of the term is very extensive. That is education of development as lecturer training as an independent field of study of own content. Integration is another expression used for education which means main streaming. The very term integration signifies the process establishment of disabled children with the normal children in the same educational setting. Special education refers to instruction that is specifically designed to meet the needs of exceptional children. It involves designing the physical environment in the classroom teaching procedures, teaching content and equipment for a particular type of disability. An exceptional child is who deviate physical, intellectual and social marked by normal growth and development that can't be benefited from regular classroom programmed and needs special treatment in school. This study aimed to create a profile of difficulties of totally visual impaired students from childhood with a vision to inform future services and to raise awareness of the need for comprehensive assessment including developmental remediation and educational advice.
\end{abstract}

Key Words: Education, Disability and Visual Impaired.

\section{Introduction}

Education in its general sense is a form of learning in which the knowledge, skills, and practice of a group of people are transferred from one generation to the next through teaching, training, or research. What is Education of development as teacher training, as an independent field of study of own content or subject of study, as a creature and creator of the society, etc. the meaning 'Education' as an independent field of study or subject is important in research viewpoint. Integration is another face used for education which means main streaming. The very term integration signifies the process of interaction of disabled children and normal children in the same educational setting.

Integrated education movement flows directly from the recognition of equal fights for all citizens and equal educational opportunity for all children with special needs, their education should be provided in the least restrictive and effective environment. It refers to integrating the physical and extra help for the disabled. It refers to integrating physical and mental handicapped children with the non-disabled children in regular classroom and providing specialized services to meet their special needs.

Special education refers to instruction that in specifically designed to meet the needs of exceptional children. It involves designing the physical environment in the classroom teaching procedures, teaching content and equipment for a particular type of disability. The early history of special education started with the hearing handicapped as early as 1555 when the Spanish monk Pedro pence de Leon (1520-1584) taught a small number of deaf children to read, write and speak and learn academic subjects. The Warnock committee report in 1978 broadened the thought of special education. It evolved the concept of special educational needs instead of categorization and labeling. The various forms of physical and intellectual impairment result in special educational needs.

The child with visual impairment is challenging to their parents, physicians and teachers. Standard techniques to evaluate visual function are often inadequate to describe accurately the extent and character of visual impairment. Educational approaches for intervention designed for the child with ocular causes of visual impairment are often unsuccessful. Recently, educators have developed specific instructional intervention strategies for the child with visual impairment; nevertheless, the potential for the child with visual impairment to live an independent and productive life is often not good. 


\section{Statement Of The Problem}

An in depth study of six cases of Educational difficulties of totally Visual Impaired Pupil are taken to arrive at possible causes stemming from different conditions such and intelligence, emotional factors, home conditions. School atmosphere and environment conditions to understand the nature of their personality and promoting factors for the development of talents and diagnosis the mal adjustments associated with and to suggest remedial measures for the education of their children.

\section{Objectives Of The Study}

1. To identify six cases of Educational difficulties of totally visual impaired pupils at school level.

2. To conduct and in depth study of identified cases.

3. To find out the information about the following aspects of the case.

\section{Sources Of Data}

This article is based on primary data and secondary data

\section{Sample}

After initial survey of school to select the visually impaired a sample of six cases of educational difficulties of totally visually impaired pupils at school level is taken for an in-depth study. The Jawahar blind school, Chimakurthy, Prakasam district is selected to conduct case studies.

The investigator will take the help of the teacher to study visually impaired children in their respective classes.

\section{Need Of The Study}

Visual impairedness may result in a few language different not in deficient language skills. Blindness does not result in intellectual retardation. Visually impaired children really depend more on touch to learn about their world. So there is some difference in conceptual development. Sight facilitates better perception of objects or parts of an object simultaneously whereas touch results in successive perceptions. Early training use of strategies helps children use their touch more efficiently. Personality problems are inherent conditions of visual impairments. Any social adjustment problems of blind individuals are primarily the result of society's reaction to the blind stereotype (e.g. repetitive rocking) exhibited by a few blind individuals can be an impediment in social acceptance, but behavioral techniques can diminish their occurrence. Hence an in depth study of educational difficulties of totally visual impaired students would throw light in the identification of their specific problems, causative factors and remedial measures. According to wikipedis.org, totally visual impairment is the complete lack of form and visual light perception and is clinically recorded as NLP, an abbreviation for "no light from dark, or the total inability to see visual impairment or low vision is a severe reduction in vision that cannot be corrected with standard glasses or contact lenses and reduces a person's ability to function at certain or all tasks.

India has the largest population of blind people in the world. That's over 12 million people. Most of them live in the poorest parts of the country with little or no access to even basic health care facilities. There are an estimated 45 million blind people in the world of which only $3 \%$ are children. This dramatic different in numbers of blind adults compared with children accounts in part for the relatively minor importance that has been attributed to the problem surrounding childhood blindness. Certainly, the well organized advocacy groups for the elderly in many developed countries are not matched by comparable ones for children. The result of this can be seen in the different in resources made available for health services and research for adult blindness versus childhood blindness. In India, there are 22 blind males and 28 blind females in every 100,000 population. The number of the blind in India is estimated to be 13 million and this is a growing figure.

The plight of people with vision impairment became so terrible that street begging and dependency on others became the only means of survival for many, especially those without adequate and appropriate Education during their childhood that would enhance their capability to lead noble life and also help them to earn their own meals. With this basic background in mind, it is imperative to understand the difficulties of visually impaired students, so that suggestions can be made to the concerned government agencies so that people with visual disabilities get the required support and facilities for proper education.

\section{EDUCATIONAL DIFFICULTIES}

There is unfortunately an incidence of marking out and preference in students with disability by nondisabled students. This appears to happen much more in the age groups from about the age of onset of puberty (12-13 on) than in the younger age groups, who tend to be far more accepting and helpful in their attitudes towards peers with disability. It is to some extent dependent on a sympathetic environment within the school, 
from Principal to teachers and clerical workers and ground staff, as to whether the teasing and bullying are present, or if present, allowed to continue.

These three areas have given rise to many harsh conflicts and much injury to the future educational and social scenario of the student for settling into the educational environment and accessing education at a suitable level with all supports required. There are disappointments for parents of children with disability, leading to impulsive emotions and many failed hopes and expectations. Serenity and practicality have to be at a premium. Often both sides are pushed to the limit in trying to reach a decision which meets their needs and the appropriate educational needs of the child. Many buildings used for child care and pre-schools, schools, and premises used by adult and community education providers are not physical accessible. Many of these do not provide themselves to modification, or modification would necessitate enormous expenditure.

Insufficient provision of funds is the biggest issue in providing equal access to education for students with disability. There are not sufficient numbers of teachers' Aides or Integration Aides available at all to meet the need. Of those there are, there is insufficient training and professional support provided for them. There are problems in determining who undertakes these procedures, whether it is teachers, parents, health personnel, specially employed and credentialed staff, and in some areas, unresolved issues to pays the cost of these services.

There is common agreement at all levels of the education spectrum that some disabilities are more challenging than others, these are: behavior problems, including Attention Deficit Disorder, Autism, learning difficulties, Deafness and psychiatric problems. Some teachers find it challenging to incorporate students with intellectual disability in a regular class, because of the scope and amount of curriculum adaptation needed in the one class.

\section{Definitions Of Visual Impairment}

Although this study is specifically targeted for students with total visual impairment, it is felt by the researcher to provide broad definitions of visual impairment from various online sources as follows:

1. Impairment of the sense of sight.

2. Visual impairment (vision impairment) is vision loss (of a person) to such a degree as to qualify as an additional support need through a significant limitation of visual capability resulting from disease, trauma or congenital or degenerative conditions that cannot be corrected.

3. Is often defined clinically as a visual acuity of $20 / 70$ or worse in the better eye with best correction, or a total field loss of $140^{\circ}$. Additional factors influencing visual impairment might be different sensitivity, light sensitivity, glare sensitivity, and light/dark adaptation.

4. A person having no light perception, or having lightinsight, but not able to count the fingers of a hand correctly (using the glasses if ordinarily used) from a distance of 3 meters in good daytime with both eyes open.

5. A significant limitation of visual capacity, including those with low vision or blindness, usually brought about by degenerative or congenital disorders, or through trauma.

6. Including blindness means impairment invasions that, even with correction, adversely affect a child's educational performance. The term includes both partial sight and blindness.

7. Loss or partial loss of vision.

Reduced vision as a result of a disorder or disease of the eye or the brain of a person can be registered "blind" on the advice of an ophthalmologist if they cannot see the biggest letter on a standard (snellen) letter chart with both eyes open when it is held $3 \mathrm{~m}$ away.

\section{Findings And Suggestions For Further Research}

1)A survey of rehabilitation programmes for visually impaired children can be taken up.

2)A study of adjustment of the visually impaired children can be taken up.

3) Comparative personality characteristics of visually handicapped adolescents can be taken up.

4) The preparation of teaching - learning packages for visually impaired children can be taken up.

5)Experimental studies on the efficacy of enrichment programmers can be taken up for the talented visually impaired children.

6) Vocational development programmes for visually impaired children can be taken up.

7)A survey of needs and problems of talented visually impaired children can be taken up.

8) Guidance and counseling intervention programmes can be taken for visually impaired children with serious problems. 


\section{Conclusion}

The need for mutual service provision is great in supporting students with disability. In many cities, towns, areas and regions, the needed coordination between education, health and community services is nonexistent.

There is a very great need for more services and more widespread and proper services to assist students with disability in three main phases of moving from one level of education to the next. They are all of major significance in the student's settling efficiently into the next level. The first transitional phase is from early childhood services preschool into primary school. This phase can make or break the young child's early entry into the formal school system. The second, a difficulty for all students, is the progression from primary school to High School. The third, a very crucial stage, is the transition from school to work, training, pre-employment training, vocational education, academic course, or adult and community education. There is a need for far more services in this area, to enable people with disability to either obtain the means to earning a living or providing meaningful activity to the extent appropriate, to fill in their days in a useful fashion.

Preventing blindness increases access to education, employment and prosperity and enables greater participation in civil, social and political life.

\section{Bibliography}

[1]. Arvind, Rai, N. Desai (1995), Helping the Handicapped Problems and Prospects. Ashish Publishing House, New Delhi.

[2]. Bharat sigh (2004), Modern Special Education, Anmol Publications Pvt. Ltd, New Delhi.

[3]. Chintamani Kar, (1992), Modern Educational Psychology, Arya Book Depot, New Delhi.

[4]. Dr. Dibakar Kundu (1991), Modern Educational Psychology, Arya Book Depot, New Delhi.

[5]. Jangira, N. K. and others, (1988), Slource Book for Teaching Visually Disabled Children. N. C. E. R. T., New Delhi.

[6]. K.C. Panda (1997), Education of Exceptional Children, Vikas Publishing House Pvt. Ltd, New Delhi.

[7]. Rama Mani, (1988), Visually Impaired in India Policy and Programmed, Ashish Publishing House, Delhi.

[8]. Samuel, A. Krik, (1962) Educational Exceptional Children, Oxford and IBH Publishing Co., New Delhi.

[9]. SA. Prameela (Nov, 2005), Perspectives on Integrated Educational Concept of Special Education, Edutracks Vol - 2, 7 - 9 pp. 